\title{
Etiologies of abdominal pain emergencies in pediatrics
}

\author{
Hala Atta Youssef ${ }^{1 *}$, Aishah Mohammad Alkhaldi², Manar Mohammed Alshahrani ${ }^{3}$, \\ Abdullah Tariq Almalki ${ }^{4}$, Amjad Ali Alahmari ${ }^{5}$, Nermeen Nasser Alrajhi ${ }^{6}$, \\ Layla Yasin Alsomali ${ }^{7}$, Turki Sanat Alharbi ${ }^{8}$, Mohammad Khaled Alkhater', \\ Sawsan Saeed Bu Sarair ${ }^{7}$, Ghadeer Ali Alghanem ${ }^{7}$, Almoutazbillah Abdulrhman Khedrawi ${ }^{1}$
}

\author{
${ }^{1}$ Department of Pediatrics, Al Aziziyah Children Hospital, Jeddah, Saudi Arabia \\ ${ }^{2}$ Sulaimaniya Primary Healthcare, Ministry of Health, Hafer Albatin, Saudi Arabia \\ ${ }^{3}$ Department of Nephrology, King Fahad General Hospital, Jeddah, Saudi Arabia \\ ${ }^{4}$ College of Medicine, King Abdulaziz University, Rabigh, Saudi Arabia \\ ${ }^{5}$ College of Medicine, King Khalid University, Abha, Saudi Arabia \\ ${ }^{6}$ College of Medicine, King Saud Bin Abdulaziz University for Health Sciences, Jeddah, Saudi Arabia \\ ${ }^{7}$ College of Medicine, Medical University of Warsaw, Warsaw, Poland \\ ${ }^{8}$ Department of Emergency Medicine, Albadaya Hospital, Badaya, Saudi Arabia \\ ${ }^{9}$ Department of Pediatrics, Al-Amiri Hospital, Kuwait City, Kuwait
}

Received: 20 September 2021

Revised: 05 October 2021

Accepted: 06 October 2021

\author{
*Correspondence: \\ Dr. Hala Atta Youssef, \\ E-mail: halayoussef130@yahoo.com
}

Copyright: (c) the author(s), publisher and licensee Medip Academy. This is an open-access article distributed under the terms of the Creative Commons Attribution Non-Commercial License, which permits unrestricted non-commercial use, distribution, and reproduction in any medium, provided the original work is properly cited.

\begin{abstract}
Reports showed that children usually complained of acute abdominal pain, which indicated the presence of severe underlying conditions and can have significant clinical importance. Serious challenges have been reported in healthcare settings where an urgent evaluation of the cases was necessary to adequately manage the patient before developing serious complications that might even end up with death. Some of these conditions included intussusception, appendicitis, volvulus and adhesions. Although estimates indicated that only around $1 \%$ of pediatric patients with acute abdominal pain usually required surgical intervention, concerns regarding the overlooking and misdiagnosis of significant conditions that might have severe prognostic outcomes were aroused among the different emergency departments. This study reviewed the common causes of acute abdominal pain among children admitted to the emergency department. Our results indicated that various etiologies can develop acute abdominal pain and therefore, establishing an adequate diagnosis by differentiating between the different etiologies should be done by the attending physicians to enhance the outcomes and adequately manage the admitted patients. Gastrointestinal causes of acute abdominal pain were the commonest to cause admissions to the emergency department. However, care should also be provided to the less common conditions, which might include genitourinary and pulmonary disorders and therefore, a thorough examination of children should be provided not to conduct a misdiagnosis of the underlying condition.
\end{abstract}

Keywords: Acute abdominal pain, Emergency, Pediatrics, Management, Diagnosis

\section{INTRODUCTION}

Reports show that children usually complain of acute abdominal pain, which can indicate the presence of severe underlying conditions and can have significant clinical importance. However, the diagnosis of the underlying condition causing acute abdominal pain is sometimes challenging due to of the various conditions that might be associated with acute abdominal pain. Fortunately, among 
the reported causes for acute abdominal pain, many of them attribute to benign and self-limiting manifestations, as in cases of viral infections and gastroenteritis. ${ }^{1}$

Serious challenges have been reported in healthcare settings where an urgent evaluation of the cases is necessary to adequately manage the patient before developing serious complications that might even end up with death. Some of these conditions include intussusception, appendicitis, volvulus and adhesions. ${ }^{1,2}$ Although estimates indicate that only around $1 \%$ of pediatric patients with acute abdominal pain usually require surgical intervention, concerns regarding the overlooking and misdiagnosis of significant conditions that might have severe prognostic outcomes were aroused among the different emergency departments. ${ }^{3}$ In the present literature review, we aimed to discuss based on evidence from the relevant investigations about etiologies of abdominal pain emergencies in pediatrics.

\section{METHODS}

This literature review was based on an extensive literature search in Medline, Cochrane and EMBASE databases which was performed on 15 September 2021 using the medical subject headings (MeSH) and a combination of all possible related terms according to the database. To avoid missing poetential studies, a further manual search for papers was done through Google Scholar and the reference lists of the initially included papers. Papers discussing etiologies of abdominal pain emergencies in pediatrics were screened for useful information, with no limitations placed on date, language, age of participants or publication type.

\section{DISCUSSION}

Emergency admissions secondary to abdominal pain in pediatric patients were attributable to many causes that have been reported in the literature (Figure 1). The attending physicians should adequately establish a differential diagnosis before initiating the management plan. In such cases, emergent approaches should be applied to the patient and therefore, being wellacquainted about the probable causes of abdominal pain in these patients will facilitate the management process in these patients. In the following section, we will discuss the different etiologies that might be the reason for admission to the emergency department of pediatric patients.

\begin{tabular}{|c|c|c|}
\hline Gastrointestinal & Genitourinary & Metabolic: \\
\hline Appendicitis & Urinary tract infoction & Diabetic ketaacidosis \\
\hline Abdominal trauma & Nephrodithiasis & Hypoghycemia \\
\hline Incarcerated hernia & Dysmenorritiea & Acute adrenal insufficiency \\
\hline Intussusception & Pelvic inflammatory disease & Acute poxphyria \\
\hline Volvulus & Mittelschmerz & Neurokgic \\
\hline Meckel's diverticulitis & Ectopic pregnancy & Abdominal epilepsy \\
\hline Necrotizing enterocolitis & Ovarian/testicular torsion & Abdominal migraine \\
\hline Intestinal perforation & Cardiac & Herpes zoster \\
\hline Inflammatory bowel disease & Mypocarditis & Radiculitis \\
\hline Gastroenteritis & Pericarditis & Nenc toot compression \\
\hline Constipation & Endocarditis & Toxins and drugs \\
\hline Peritonitis & Congestive heart failure & Lead poisoning \\
\hline Peptic ulcer & Pulmonary & Venoms \\
\hline Mesenteric lymphadenitis & Lower lobe pneumonia & Erythromycin \\
\hline Hepatobiliary, splenic, pancteatic & Pneumothorax & Salicylates \\
\hline Hepatitis & Diagphragmatic pleurisy & Miscellanevus \\
\hline Liver abscess & Hematologic & Infantile colic \\
\hline Cholecytitis & Sickle cell anemia & Pharyngitis \\
\hline Cholelithiasis & Hemolytic uremic syndrome & Functional pain \\
\hline Splenix infarction & Acute leukemia & Angioneurotic edema \\
\hline Splenic rupture & Henoxh-Schölein purpura & \\
\hline Pancreatitis & Vasoocdusive crisis & \\
\hline
\end{tabular}

Figure 1: Causes of acute abdominal pain in children. ${ }^{4}$

Among the variously reported reasons, appendicitis has been reported as a potential and common cause to occur in such settings. The primary pathology that led to the development of the condition was obstruction of the lumen of the appendix by stool parasites, food or barium. Although the condition was a prevalent in the emergency department and can impact the different age groups, estimates indicated that it rarely affected young infants. In a previous COHORT investigation in Sweden, it had been demonstrated that by the age of 18 years old, only $2.5 \%$ of these children suffered from appendicitis. ${ }^{5}$ The prognosis of the condition was a good one on the 
condition that it was surgically managed. However, negligence in some cases might lead to the development of necrosis secondary to ischemia that might end up with perforation, which might be a life-threatening condition. It had been previously demonstrated that the risk of perforation significantly increased with any delay in applying the surgical interventions. ${ }^{6}$ A previous investigation also reported that around $30 \%$ of infantile cases with appendicitis usually suffered from perforation. ${ }^{7}$ Inflammation of the mesenteric lymph nodes or mesenteric adenitis might also be memic appendicitis, and estimates show that $23 \%$ of these patients have mistakenly undergone an appendectomy. ${ }^{8}$ However, a previous comparative investigation had elaborated that patients with mesenteric adenitis might also present with symptoms like dysuria and a high fever that does not usually manifest in patients with appendicitis, in addition to the less frequency of other symptoms like vomiting, migratory pain and other local symptoms that were indicative of the presence of appendicitis. ${ }^{9}$

Intussusception might also be the reason for the emergency admission secondary to acute abdominal pain in children. It mostly affected the ileocecal region and occured when a segment telescopes or invaginates within another distal segment leading to the formation of intussusception. Estimates indicated that the condition usually affected 3-12 month old infants and the prevalence of the condition had been reported to be highest at 5-7 months old. ${ }^{10}$ Patients might present with a variety of non-specific symptoms and it had been reported that observing colicky pain, fever, leg flexion, vomiting and lethargy should direct attending physicians to the diagnosis of intussusception. The etiology of intussusception also differed based on the age of the affected child and the primary pathology of intussusception was most probably attributable to the presence of mesenteric lymphadenopathy. This had been reported for $<2$ year old children. It was also the common cause in older children. However, other disorders have also previously been reported including Meckel's diverticulum and intestinal lymphoma. Therefore, these older children should be evaluated for the presence of a malignant diagnosis whenever they have presented with ileoileal or jejunojejunal intussusceptions. HenochSchonlein's purpura might also be a direct cause for the development of ileoileal intussusceptions. Meckel's diverticulum usually arose from the antimesenteric border as a finger-like projection within the distal ileum and was usually $2 \mathrm{~cm}$ wide, $1-10 \mathrm{~cm}$ long and 40-60 $\mathrm{cm}$ away from the ileocecal valve. Estimates indicated that most children, when affected by the condition usually presented to the emergency department before the age of 2 years old, with an estimated prevalence rate of $3 \% .^{11}$ Investigations also indicated that more than one-third of the affected children usually presented with intestinal obstruction, which was also another medical emergency that needs urgent interventions. ${ }^{12,13}$
Intestinal obstruction can affect both the large and small intestine and was attributable to different etiologies that can severely affect the patient's health and can even end up with death in some cases and therefore, it always required the application of emergent management approaches. Different pediatric ages can be affected by this condition and the condition might be asymptomatic in some cases. ${ }^{14}$ However, this might mask the severity of the disease until intestinal ischemia occured and/or severe abdominal distension which can severely impact the affected patient's health. However, it had been demonstrated that the condition might be similar to intestinal ileus, which was considered a mild condition that did not usually require surgical intervention. Acquired and congenital causes might be attributable to the development of intestinal obstruction and atresia and stenosis were the main congenital causes that affected newborn patients. ${ }^{15,16}$ Partial and complete obstruction might occur secondary to duodenal stenosis or atresia which occured due to failure of recanalization during the developmental period. Therefore, this might be associated with incomplete obstruction or stenosis of the duodenal lumen, allowing for some fluids and gases to pass or complete obstruction of the lumen where nothing can pass beyond the point of obstruction. The same events also occured anywhere in the jejunum and ileum leading to partial or complete obstruction in the affected regions. However, it had been demonstrated that avascular disorder might be the main reason for developing this condition during development. Different types of hernias can also be complicated by intestinal obstruction. As for the colon, evidence showed that complete colonic atresia can affect any part of it. However, it usually occured next to the splenic flexure. A vascular disorder might also attribute to the development of the condition during development. It had been further demonstrated that within the neonatal period, meconium ileus can also lead to the development of congenital intestinal obstruction. The clinician should also consider the presence of an underlying pancreatic condition, in addition to adequately evaluating patients for the presence of cystic fibrosis. ${ }^{17,18}$ Other congenital causes that might lead to the development of intestinal obstruction might also include duplication cysts and evidence also indicated that intussusception and volvulus might also be associated. Other conditions that might also be associated included hemorrhage, peptic ulcer disease and perforation that might significantly lead to the development of peptic ulcer mucosa. On the other hand, tumors, incarcerated or strangulated hernias and small bowel adhesions might be attributable to the development of acquired intestinal obstruction. Tumors might be extra-intestinal or within the lumen and acquired causes can occur at any age. ${ }^{19}$ Taking adequate history from the patient can help the physician establish an adequate diagnosis. For instance, having a history of necrotizing enterocolitis or surgical interventions can lead to the presence of adhesive intestinal obstruction. The presence of omental cysts might also be the underlying cause of intestinal obstruction and a differential diagnosis should be 
conducted with the presence of ovarian cysts. Furthermore, meconium ileus-equivalent syndrome or distal intestinal obstruction syndrome were two terms that have been used in the literature to describe the occurrence of partial bowel obstruction in patients with cystic fibrosis. ${ }^{20,21}$ However, it should be noted that this event was not necessarily related to the presence of meconium. In these situations, distal bowel obstruction was the main pathology that led to distal bowel obstruction and can affect both adults and adolescents suffering from cystic fibrosis disease.

It had been furtherly demonstrated that volvulus can affect children at different age groups, However, estimates showed that it usually affected children that were $<1$ year old and evidence indicated that it occured within the 1 st month of life in $60 \%$ of the cases. ${ }^{22}$ Some inflammatory diseases and conditions might also attribute to the development of acute severe abdominal pain in children, including necrotizing enterocolitis, inflammatory bowel diseases, celiac disease, peptic ulcer disease, cholecystitis and/or cholelithiasis and biliary dyskinesia. ${ }^{23-26}$ Furthermore, evidence also indicated some hepatic viral infections might be associated with severe abdominal pain. Acute pancreatitis was also a potential etiology that might cause acute abdominal pain and is attributed to different etiologies including drug administration, inflammation, infections and trauma. ${ }^{26}$ The condition can furtherly lead to other complications, which might be life-threatening and therefore, early prompt management should be offered to the affected patients. Children might also suffer from splenic cysts and infarctions and estimates indicated that acquired and congenital cysts attributed to the most etiologies of splenic masses in children. Pediatric patients might also present to the emergency department secondary to abdominal trauma as demonstrated in a previous investigation that estimated that $3 \%$ of children within the trauma pediatric department were attributed to abdominal trauma. ${ }^{27}$

Studies in the literature have also indicated the high prevalence of genitourinary causes as potential etiologies for admission to the emergency department. Urinary tract infections, nephrolithiasis and primary dysmenorrhea were common causes among children and can attribute to the development of acute abdominal pain and potential admission to the emergency department. ${ }^{28,29}$ Evidence also indicated that testicular torsion was a significant cause for children to be admitted to the emergency department because the condition can significantly lead to necrosis of the testicular tissues. ${ }^{30}$ In females, ruptured ovarian cysts can also be the presenting etiology and the cause of pain in these cases would be the associated hemorrhage that induced peritonitis. It should be noted that a differential diagnosis should be established between this case and the case of ruptured ectopic pregnancy. ${ }^{31,32}$ Ovarian torsion had also been previously reported and usually affected female children within the early reproductive age. ${ }^{33}$ Estimates also showed that pelvic inflammatory diseases were potential causes for admission to the emergency department and it had been demonstrated that such events were more frequent in adolescents than older population and were usually attributable to sexually transmitted diseases. ${ }^{34}$ Etiologies related to the complications of pregnancy were also wellknown causes of acute abdominal pain. Some of these might include ectopic pregnancy and miscarriage and in these situations, vaginal bleeding and amenorrhea were usually associated manifestations. ${ }^{35,36}$ Pulmonary causes as recurrent pneumonia and causes of functional abdominal pain as irritable bowel syndrome and functional dyspepsia were also reported in the literature as potential causes of acute abdominal pain in the pediatric population. ${ }^{37,38}$

\section{CONCLUSION}

Various etiologies can develop acute abdominal pain and therefore, establishing an adequate diagnosis by differentiating between the different etiologies should be done by the attending physicians to enhance the outcomes and adequately manage the admitted patients. Gastrointestinal causes of acute abdominal pain are the commonest to cause admissions to the emergency department. However, care should also be provided to the less common conditions, which might include genitourinary and pulmonary disorders and therefore, a thorough examination of children should be provided not to conduct a misdiagnosis of the underlying condition.

Funding: No funding sources

Conflict of interest: None declared

Ethical approval: Not required

\section{REFERENCES}

1. D'Agostino J. Common abdominal emergencies in children. Emerg Med Clin North Am. 2002;20(1):139-53.

2. Grant HW, Parker MC, Wilson MS, Menzies D, Sunderland G, Thompson JN, et al. Adhesions after abdominal surgery in children. J Pediatr Surg. 2008;43(1):152-6.

3. Scholer SJ, Pituch K, Orr DP, Dittus RS. Clinical outcomes of children with acute abdominal pain. Pediatrics. 1996;98:680-5.

4. Kim JS. Acute abdominal pain in children. Pediatr Gastroenterol Hepatol Nutr. 2013;16(4):219-24.

5. Omling E, Salö M, Saluja S, Bergbrant S, Olsson L, Persson A, et al. Nationwide study of appendicitis in children. British J Surg. 2019;106(12):1623-31.

6. Papandria D, Goldstein SD, Rhee D, Salazar JH, Arlikar J, Gorgy A, et al. Risk of perforation increases with delay in recognition and surgery for acute appendicitis. J Surg Res. 2013;184(2):723-9.

7. Howell EC, Dubina ED, Lee SL. Perforation risk in pediatric appendicitis: assessment and management. Pediatric Health Med Ther. 2018;9:135-45. 
8. Karabulut R, Sonmez K, Turkyilmaz Z, Demirogullari B, Ozen IO, Demirtola A, et al. Negative appendectomy experience in children. Ir J Med Sci. 2011;180(1):55-8.

9. Gross I, Siedner-Weintraub Y, Stibbe S, Rekhtman D, Weiss D, Simanovsky N, et al. Characteristics of mesenteric lymphadenitis in comparison with those of acute appendicitis in children. Eur $\mathrm{J}$ Pediatr. 2017;176(2):199-205.

10. Jiang J, Jiang B, Parashar U, Nguyen T, Bines J, Patel MM. Childhood intussusception: a literature review. PloS One. 2013;8(7):68482.

11. Hansen CC, Søreide K. Systematic review of epidemiology, presentation, and management of Meckel's diverticulum in the 21st century. Medicine. 2018;97(35):12154.

12. Elsayes KM, Menias CO, Harvin HJ, Francis IR. Imaging manifestations of Meckel's diverticulum. AJR Am J Roentgenol. 2007;189(1):81-8.

13. Lin XK, Huang XZ, Bao XZ, Zheng N, Xia QZ, Chen CD. Clinical characteristics of Meckel diverticulum in children: A retrospective review of a 15-year single-center experience. Medicine. 2017;96(32):7760.

14. Smith DA, Kashyap S, Nehring SM. Bowel Obstruction. Treasure Island (FL): StatPearls Publishing; 2021.

15. Reddy SR, Cappell MS. A systematic review of the clinical presentation, diagnosis, and treatment of small bowel obstruction. Curr Gastroenterol Rep. 2017;19(6):28.

16. Cappell MS, Batke M. Mechanical obstruction of the small bowel and colon. Med Clinic North Am. 2008;92(3):575-97.

17. Waldman AR. Bowel obstruction. Clinic J Oncol Nurs. 2001;5(6):281-2.

18. Baron TH. Acute colonic obstruction. Gastrointest Endosc Clin North Am. 2007;17(2):323-39.

19. Canon CL, Baron TH, Morgan DE, Dean PA, Koehler RE. Treatment of colonic obstruction with expandable metal stents: radiologic features. AJR Am J Roentgenol. 1997;168(1):199-205.

20. Barth $X$. Intestinal obstruction of the colon: physiopathology, etiology, diagnosis, treatment. La Revue Praticien. 2001;51(7):783-7.

21. Casa C, Arnaud JP. Intestinal obstruction of the colon. Physiopathology, etiology, diagnosis, treatment. La Revue praticien. 1997;47(16):1833-6.

22. Shalaby MS, Kuti K, Walker G. Intestinal malrotation and volvulus in infants and children. BMJ. 2013;347:6949.

23. Neu J, Walker WA. Necrotizing enterocolitis. New England J Med. 2011;364(3):255-64.

24. Sullivan PB. Peptic ulcer disease in children. Paediatr Child Health. 2010;20(10):462-4.

25. Singh P, Arora A, Strand TA, Leffler DA, Catassi C, Green $\mathrm{PH}$, et al. Global Prevalence of celiac disease: systematic review and meta-analysis. Clinic Gastroenterol Hepatol. 2018;16(6):823-36.

26. Suzuki M, Sai JK, Shimizu T. Acute pancreatitis in children and adolescents. World J Gastrointest Pathophysiol. 2014;5(4):416-26.

27. Bradshaw CJ, Bandi AS, Muktar Z, Hasan MA, Chowdhury TK, Banu T, et al. International study of the epidemiology of paediatric trauma: PAPSA Research Study. World J Surg. 2018;42(6):1885-94.

28. Ladomenou F, Bitsori M, Galanakis E. Incidence and morbidity of urinary tract infection in a prospective COHORT of children. Acta Paediatrica. 2015;104(7):324-9.

29. DeSanctis V, Soliman A, Bernasconi S, Bianchin L, Bona G, Bozzola M, et al. Primary dysmenorrhea in adolescents: prevalence, impact and recent knowledge. Pediatr Endocrinol Rev. 2015;13(2):512-20.

30. Lavallee ME, Cash J. Testicular torsion: evaluation and management. Curr Sport Med Rep. 2005;4(2):102-4.

31. Boyle KJ, Torrealday S. Benign gynecologic conditions. Surg Clin North Am. 2008;88(2):245-64.

32. Kelleher CM, Goldstein AM. Adnexal masses in children and adolescents. Clinic Obstetr Gynecol. 2015;58(1):76-92.

33. Emeksiz HC, Derinöz O, Akkoyun EB, Güçlü Pınarlı F, Bideci A. Age-specific frequencies and characteristics of ovarian cysts in children and adolescents. J Clinic Res Pediatr Endocrinol. 2017;9(1):58-62.

34. Das BB, Ronda J, Trent M. Pelvic inflammatory disease: improving awareness, prevention, and treatment. Infect Drug Resist. 2016;9:191-7.

35. Bouyer J, Coste J, Fernandez H, Pouly JL, Job-Spira N. Sites of ectopic pregnancy: a 10 year populationbased study of 1800 cases. Human Reproduct. 2002;17(12):3224-30.

36. Gaskins AJ, Missmer SA, Rich-Edwards JW, Williams PL, Souter I, Chavarro JE. Demographic, lifestyle, and reproductive risk factors for ectopic pregnancy. Fertil Steril. 2018;110(7):1328-37.

37. Rasquin A, DiLorenzo C, Forbes D, Guiraldes E, Hyams JS, Staiano A, et al. Childhood functional gastrointestinal disorders: child/adolescent. Gastroenterol. 2006;130(5):1527-37.

38. Boronat AC, Ferreira-Maia AP, Matijasevich A, Wang YP. Epidemiology of functional gastrointestinal disorders in children and adolescents: a systematic review. World J Gastroenterol. 2017;23(21):3915-27.

Cite this article as: Youssef HA, Alkhaldi AM, Alshahrani MM, Almalki AT, Alahmari AA, Alrajhi $\mathrm{NN}$, et al. Etiologies of abdominal pain emergencies in pediatrics. Int $\mathrm{J}$ Community Med Public Health 2021;8:5568-72. 